\title{
Never See an Adult Again
}

\author{
Himanshu Agrawal ${ }^{1}$
}

Received: 23 November 2020 / Accepted: 25 May 2021 / Published online: 8 June 2021

(C) Academic Psychiatry 2021

According to the American Psychiatric Association, 50\% of all psychiatric disorders begin before age $16,75 \%$ by the mid 20s [1]. Additionally, there is a strong argument that many psychiatric disorders of adulthood are chronic diseases of childhood [2]. The Diagnostic and Statistical Manual, Fifth Edition (DSM-5) lists 20 separate neurodevelopmental disorders (NDDs), most of which persist in adulthood. For example, $60 \%$ of individuals with disorders such as attention deficit hyperactivity disorder (ADHD), while not meeting full criteria for their previous diagnosis, still have impairing symptoms that persist into adulthood and require treatment [3]. Most individuals with autism spectrum disorder and intellectual disability grow into adulthood, and individuals with some form of a developmental disability account for approximately $17 \%$ of the population [4]. Many with NDDs have comorbidities along with the primary disorders that require care. If this is not enough, there is growing evidence that many other disorders described in the DSM-5 may be neurodevelopmental disorders; these include schizophrenia, bipolar disorder, and mood and anxiety disorders [5].

It is a common observation and complaint that there are very few child psychiatrists in the USA that see solely kids. I see it a bit differently. Ever since I completed my fellowship in child and adolescent psychiatry, I actually have never seen a single adult in my practice. Now, a quick audit of my practice will reveal that two-thirds of my patients are over the age of 18. Yet, I stand behind my assertion: I never see adults any longer. Only children that have grown up. And in some instances - have not.

To begin with, I moved halfway across the globe so I may get the kind of psychiatric training I craved. Long, languid sessions with people who needed to be heard. Ample time to dive into their biological, psychological, and social worlds. Like-minded mentors who saw the best in me and challenged

Himanshu Agrawal

hagrawal@mcw.edu

1 Medical College of Wisconsin, Milwaukee, WI, USA me to be better. I am delighted to share that the training experience was everything I had hoped for.

Having said that, it appears to me that in my psychiatric training, I studied the human condition in reverse chronological order. As a fellow in child and adolescent psychiatry, the more I immersed myself into the world of emotional and behavioral development, the more I found myself re-imagining what my patient care would have looked like with adult patients I had seen during residency. Now that I was being taught in greater detail how to study the developmental trajectory of individual beings, I started realizing that I would have approached my adult patients with a very different perspective, starting with a curiosity about their beginnings. It took me specific training in my child and adolescent fellowship to go beyond lip service to phrases such as "childhood matters" and "the best predictor for the future is the past."

My fellowship training in child and adolescent psychiatry helped me understand the deeper meaning behind the quote, "What the eye doesn't see and the mind doesn't know, doesn't exist" (D. H. Lawrence). Consider the social history section in a medical note. There is very little literature that discusses the importance of this section. I have often heard my general psychiatry colleagues complain that many non-psychiatrists do this section disservice by limiting it to a few perfunctory lines about marital status, employment, and substance use. As a child psychiatrist, I am tempted to make a similar remark about many of my psychiatry colleagues. From what I've observed, many psychiatrists do not describe the biological, psychological, or social aspects of the mother's pregnancy, our adult patient's entry into the world (the delivery) or the all-important early years of the patient's life. Often, there is not much in terms of a sophisticated exploration of the dynamics with important figures in the young child's life (beyond some perfunctory phrases such as "overbearing mother" or "distant father"), even though we can agree that these initial psychological experiences have a profound relationship with the adult patient's symptoms and prognosis, their strengths, and their fragilities. 
If I could have my way, I would ensure that the first 12 months of a psychiatric training were solely dedicated to child and adolescent psychiatry. Since this wish may be unrealistic and unfeasible, and may require a significant shift in training practices, perhaps a good place to start might be for certain creative program directors to consider redesigning their general psychiatry residency program with a novel emphasis on normal development and developmental psychopathology, one psychiatric condition at a time.

If you are a psychiatry resident, I urge you to consider a fellowship in child and adolescent psychiatry. Sure, it makes for a slightly longer journey. However, I assure you, the personal and professional rewards can be well worth it.

Indeed, over the past 13 years, thanks to my additional training in child and adolescent psychiatry, my practice has served people who range in age from 3 to 93 years and who are either children, children that have grown up, or children who have not grown up because of the depth and breadth of developmental regression.

\section{Declarations}

Disclosures The author declares that he has no financial conflicts to disclose.

\section{References}

1. Kessler RC, Amminger GP, Aguilar-Gaxiola S, Alonso J, Lee S, Ustün TB. Age of onset of mental disorders: a review of recent literature. Curr Opin Psychiatry. 2007;20(4):359-64. https://doi. org/10.1097/YCO.0b013e32816ebc8c.

2. Costello EJ, Mustillo S, Erkanli A, Keeler G, Angold A. Prevalence and development of psychiatric disorders in childhood and adolescence. Arch Gen Psychiatry. 2003;60(8):837-44. https://doi.org/10. 1001/archpsyc.60.8.837.

3. Wilens TE, Spencer TJ. Understanding attention-deficit/hyperactivity disorder from childhood to adulthood. Postgrad Med. 2010;122(5):97-109. https://doi.org/10.3810/pgm.2010.09.2206.

4. Zablotsky B, Black LI, Maenner MJ, Schieve LA, Danielson ML, Bitsko RH, et al. Prevalence and trends of developmental disabilities among children in the US: 2009-2017. Pediatrics. 2019;144(4): e20190811.

5. Rund BR. The research evidence for schizophrenia as a neurodevelopmental disorder. Scand J Psychol. 2018 Feb;59(1): 49-58. https://doi.org/10.1111/sjop.12414.

Publisher's Note Springer Nature remains neutral with regard to jurisdictional claims in published maps and institutional affiliations. 